\title{
Vertical Handoff with Predictive Received Signal Strength in Next Generation Wireless Network
}

\author{
Jyoti Madaan \\ Manav Rachna International University, Faridabad, 121003, India \\ E-mail: madaanjyoti82@gmail.com \\ Indu Kashyap \\ Manav Rachna International University, Faridabad, 121003, India \\ E-mail: indu.fet@mriu.edu.in
}

\begin{abstract}
Since the last few decades, tremendous innovations and inventions have been observed in every field, but especially in wireless network technology. The prevailing demand curves and trends in this particular area of communication show the importance of real-time multimedia applications over several networks with guaranteed quality of service (QoS). The Next Generation Wireless Network (NGWN) consists of heterogeneous wireless networks that will grant high data rate and bandwidth to mobile users. The primary aim of Next Generation Wireless Network (NGWN) is to conceal heterogeneities and to achieve convergence of diverse networks to provide seamless mobility. So that mobile user can move freely between networks without losing the connection or changing the setting at any moment. When the mobile user moves between different networks, there is a requirement to handover the channel, from one network to another by considering its services, features and user preferences. Channel handover between two different networks is done with the help of vertical handoff (VHO). In a heterogeneous environment, numerous technologies co-exist with their unique characteristics. Therefore, it is very difficult to design efficient handoff decision algorithm. The poorly designed handoff algorithm tends to increase the traffic load and, thereby tend to dramatic decrease in quality of service. A mobile node equipped with multiple network interfaces will be able to access heterogeneous wireless access network. But the availability of alternatives give rise to a problem of unnecessary handoff. To avoid this, we have proposed a decision algorithm based on predictive received signal strength, hysteresis margin and dwell time to select an optimum target network. The handoff policies are designed using received signal strength (RSS), available bandwidth, service cost, user preference, type of application and network condition to reduce the number of handoffs, decision delay, probability of handoff failure and probability of unnecessary handoff. We have also made a comparative analysis of various vertical handoff decision algorithms in this paper.
\end{abstract}

Index Terms - Vertical Handoff Decision (VHD), Next Generation Wireless Networks (NGWNs), Quality of service (QoS), Vertical Handoff (VHO), Received Signal
Strength (RSS).

\section{INTRODUCTION}

The wireless technology beyond $4 \mathrm{G}$ is known as NGWNs, it is a composite communication model of various access systems such as Cellular, Wireless Local Area Network (WLAN), and even wired networks. Cellular network such as Universal Mobile Telecommunication System (UMTS), Code Division Multiple Access (CDMA) supports low data rate and low bandwidth over a large coverage area. While Wireless Local Area network (WLAN) supports high data rate and high bandwidth over a small coverage area. Hence, in future the users of wireless technologies will not be bound by subscription of one single network, they can choose one of the available networks depending upon the requirement at that moment. The mobile devices with multiple network interface terminals can connect to any available network (e.g. GPRS, UMTS, WLAN, Wi-MAX, Bluetooth, etc.) These wireless networks are combined to offer high data rate and best services to the mobile nodes [1]. But for accessing different wireless networks, in a heterogeneous environment of NGWNs, handoff management is the most important requirement. It controls the movement of a mobile node from one network to another during an active connection [2]. Handoff can be classified into horizontal handoff (occur in homogeneous network) and vertical handoff (occur in heterogeneous network). Horizontal handoffs are required due to unavailability of connectivity. Whereas, vertical handoffs are required to provide better service to the user rather than connectivity. The vertical handoff decision process answers When and Where to handoff in a heterogeneous network. The choice When is related to the handoff initiation. It triggers the handoff algorithm at an appropriate time to minimize traffic overhead and unnecessary handoff. The second choice Where is related to the handoff decision. It depends upon various decision criteria like received signal strength (RSS), available bandwidth, service cost, user preference, type of application and network condition. These criteria have to be evaluated and compared to detect and to trigger a handoff algorithm. For that, we explore many vertical 
handoff decision algorithms like Traditional Method, User Centric Approaches, Fuzzy Logic and Neural Network, Context Aware, Functional Based and Multiple Attributes Decision Making. The most important requirement of vertical handoff algorithm is seamless connectivity with the best available network. For that, a handoff algorithm must initiate a handoff process at the right time to choose an optimum target network for a specific application from available network.

The rest of the paper explains different types of handoff, criteria involved in vertical handoff (VHD), vertical handoff management process, comparative analysis of existing vertical handoff decision making algorithms, various research issues in vertical handoff (VHD) and a proposed algorithm.

\section{TYPES OF HANDOFF}

When a mobile node moves into a different cell during a call, the mobile switching center (MSC) automatically transfers the call to a new channel belonging to the new base station [2]. This process is known as handoff. Depending on the access network that each point of attachment belongs to, the handoff can be classified into two main categories such as horizontal handoff and vertical handoff [3]. Fig. 1 Shows, various types of handoffs.

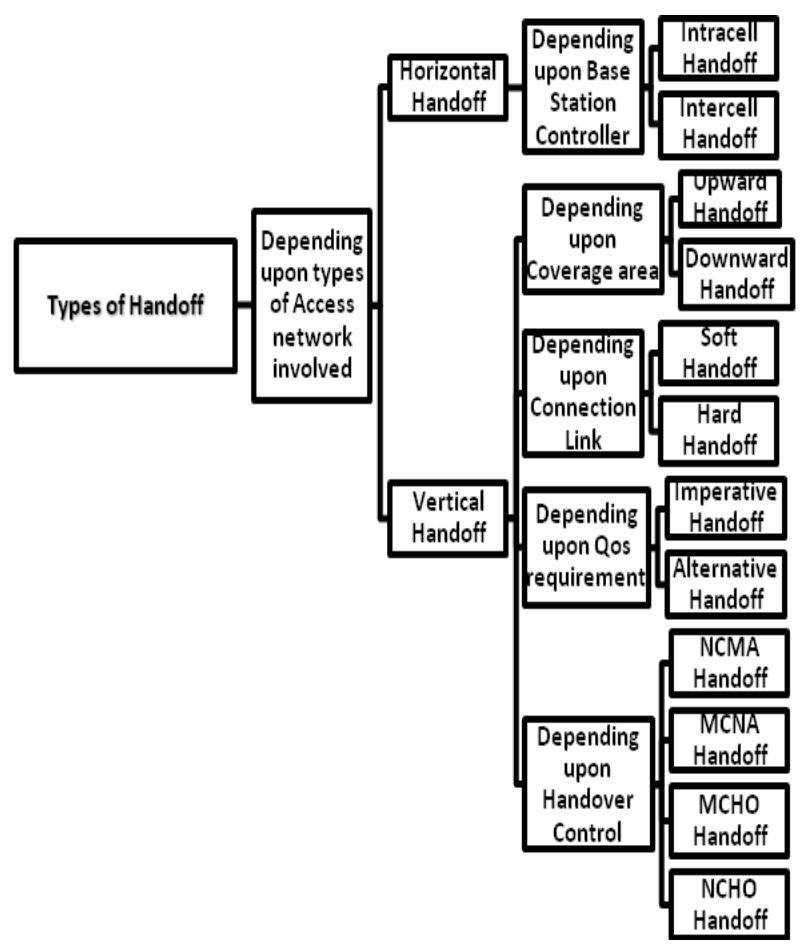

Fig.1. Types of Handoff

\section{A. Horizontal Handoff (HHO)}

Horizontal handoff occurs among two base stations (BS) of the same network (same access technology). Horizontal handoff can be further divided into Intra cell and Inter cell handoff [4]. i). Intracell handoff: It occurs when a mobile user moves to a new cell under the same base station in order to minimize inter channel interference [1].

ii). Intercell handoff: It occurs when a mobile user moves to a new cell, which is served by different base stations. All the existing connections are transferred to the new base station controller (BSC) [5].

\section{B. Vertical Handoff (VHO)}

The vertical handoff changes the mobile node active connection between various wireless access points. vertical handoff can be further classified as:

i). Upward and downward handoff: Vertical handoff can be separated as upward and downward based on the coverage of a source and target networks. In an upward handoff, the mobile device switches from smaller coverage to a larger coverage. On the other hand, in downward handoff the mobile device switches from a network of larger coverage to a smaller coverage.

ii). Hard and Soft handoff: In a hard handoff, the mobile device connects to a new base station only after disconnection from the previous base station [5]. On the other hand, in soft handoff a mobile node maintains the connection with the previous base station till it completes the connection with the new base station. This process is also called as make before break because the mobile device maintains simultaneous connections with both the base stations.

iii). Imperative and Alternative handoff: An imperative handoff occurs when signal strength from a current access point decreases. On the other hand, an alternative handoff occurs to provide the user better services. In this, handoff decision is based on various parameters like available bandwidth, threshold velocity of network, usage cost of the network, quality of service required by the application and user preferences.

iv). Mobile controlled and network controlled handoff: Handoff decision can be controlled by a mobile or network. Depending on who is controlling the handoff decision, it can be subdivided as:

a) Mobile controlled handoff (MCHO): In this, handoff decision is taken by the mobile node only [6].

b) Network controlled handoff (NCHO): The handoff decision is controlled by the network only [6].

c) Mobile controlled network assisted (MCNA): The handoff decision is taken by a mobile device, but with the help of the network. This is a more suitable method because only mobile devices have the knowledge about the network interface and user preferences [6].

d) Network controlled mobile assisted (NCMA): The handoff decision is taken by the network, but the 
data required for handoff are collected with the help of mobile device [6].

\section{CRITERIA INVOLVED IN VERTICAL HANDOFF DECISION}

In heterogeneous networks, each network has a distinct characteristic in terms of data rate, bandwidth, cost, power and security. Therefore, these characteristic have to be considered as a basis for handoff decision. Fig. 2 shows, various handoff decision parameters.

\section{A. Bandwidth:}

Bandwidth is a measure of handling the traffic load. The higher the bandwidth, lower will be call dropping and call blocking probability.

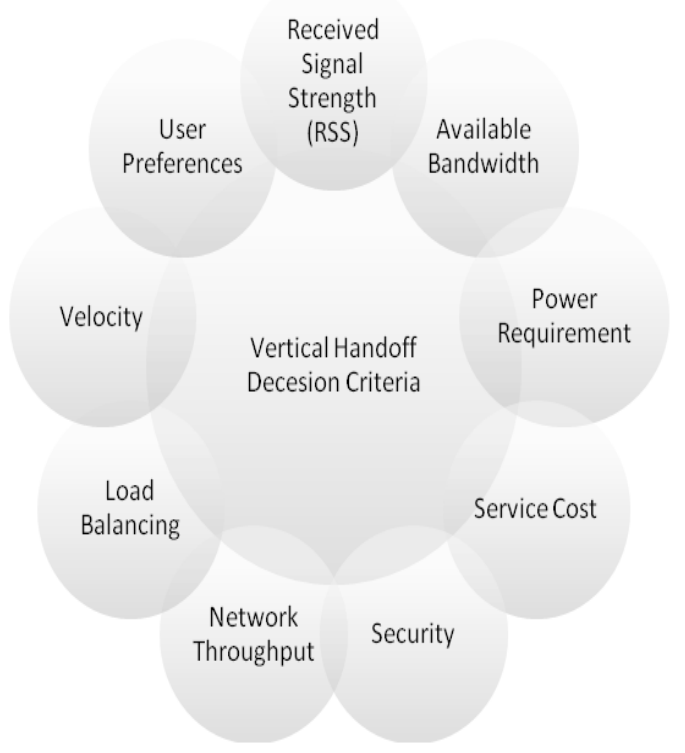

Fig.2. Vertical Handoff Decision Criteria

\section{B. Handoff Latency:}

The delay can occur during the handover of calls between two base stations. This hold up time is known as handoff latency. A high-quality handoff decision model should have minimum handoff latency.

\section{Power Consumption:}

Power is consumed when a mobile node switches between networks and during the handoff process. Therefore, when the battery level of mobile node decreases, then switching to a network having low power consumption can provide extended usage time. For example, if a mobile node battery is almost worn out, then switching from a WLAN to WWAN would be a beneficial decision [7].

\section{Network Cost:}

Vertical handoff (VHO) algorithms should consider the network cost because different charging policies are used by various access domains.

\section{E. User Preferences:}

Based on the application requirements like (voice, data, and video) the user may prefer different networks according to the network performance.

\section{F. Network Throughput:}

Network throughput is the average data rate of a particular communication link.

\section{G. Network Load Balancing:}

Network traffic must be taken into account during efficient handoff. It is essential to balance the load to avoid degradation in quality of service (QoS).

\section{H. Network Security:}

The security feature is not well built in some wireless access technologies. Therefore, to achieve the maximum level of reliability, validation and confidentiality, the network security feature should be implanted in the handoff algorithms.

\section{Received Signal Strength (RSS):}

The received signal strength (RSS) should not be underneath a certain threshold in a network throughout handoff. The received signal strength (RSS) must have to be strong enough to maintain the signal quality at the receiver.

\section{J. Velocity:}

Velocity of the mobile device is an important parameter for handoff decision [8]. For example, if a mobile device is moving at a high speed then switching to smaller coverage is not valuable because a handoff to the actual network would occur very soon [5].

It is essential to consider maximum numbers of parameters during vertical handoff (VHO). But it is difficult to consider all the metrics in a single decision model as it increases the battery requirement of the mobile device and complexity of algorithms.

\section{VeRticAl HANDOFF MANAGEMENT PROCESS}

Handoff management is a essential requirement to support mobility in Next generation network (NGWNs). It manages the connectivity of a mobile node during a movement from one network to another [9]. Fig. 3 shows the complete handoff management process. The process is divided into 3 phases as explained below:

\section{A. Phase 1 (Handoff Initiation phase)}

The first step of handoff management is to estimate handoff necessity to trigger handoff algorithm. Handoff can be initiated by the mobile node or network. Usually, a mobile node initiates the handoff whenever received signal strength of serviced network goes below a specific threshold level. While Network initiates the handover for load balancing, resource management and good QoS. In this phase, information is collected about the network and the mobile node from the upper layers such as a transport 
layer, link layer, and application layer. These layers provide the information in terms of received signal strength(RSS), power requirement, link delay, link cost, user preferences and available bandwidth in order to trigger the handoff [10]. Based on this information, the handoff will be triggered at an appropriate time.

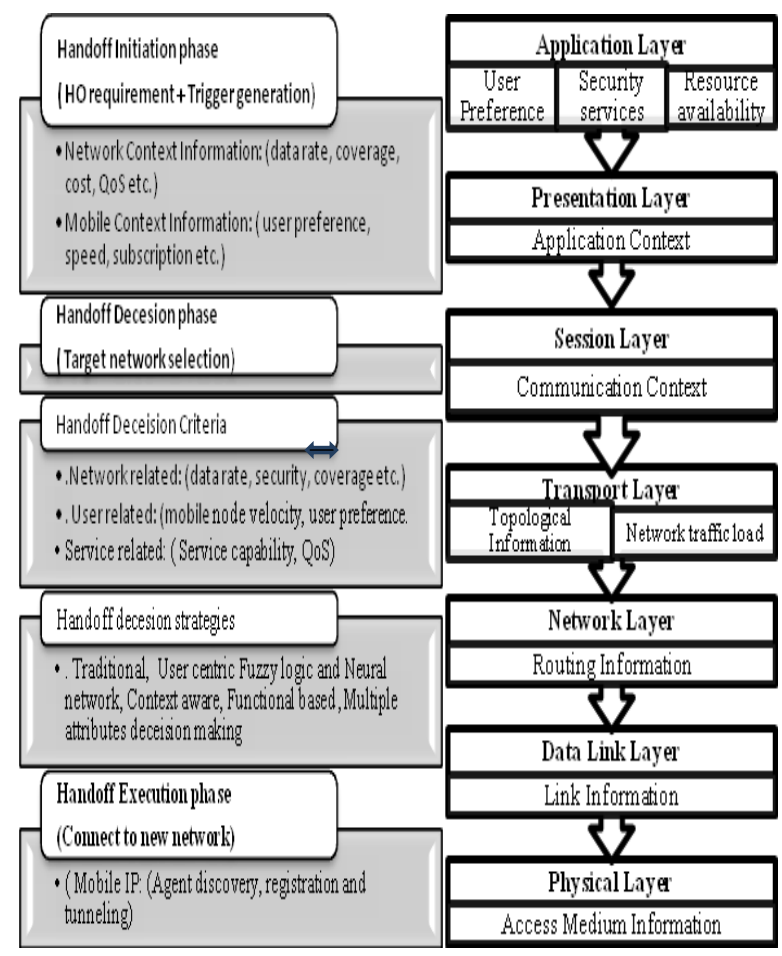

Fig.3. Vertical Handoff Management Process

\section{B. Phase 2 (Handoff Decision)}

In the second phase, the decision is taken regarding the selection of target network depending upon various handoff decision criteria (e.g. received signal strength, bandwidth, cost, security, etc.) and decision strategies (e.g. traditional approach, user centric approach, context aware approach, etc.) In this, mobile node decides whether to continue with the current network or to switch over to another network with the help of information collected during phase 1 .

\section{Phase 3 (Handoff Execution)}

In this Phase, all the mobile node active connections are transferred from the old network to the new network. This stage is responsible for re-routing of connections, agent discovery and registration of new care of address (COA) in Mobile Internet Protocol (MIP).

\section{RELATED WORK}

Lots of work has been done on vertical handoff decision algorithms and comparative analysis was also done by researchers to evaluate their performance, In [11], B. Bhowmik have made a comparative study of selective traffic models to show how a handoff procedure has a significant impact on wireless mobile network performance in terms of new call blocking probability and the forced termination of ongoing calls and the number of mobile nodes that get serviced by the underlying base station. The various vertical decision algorithms can be grouped in following six categories for comparative analysis:

A. Traditional B. User Centric C. Fuzzy Logic and Neural network D. Context Aware E. Functional based F. Multiple Attributes Decision Making

\section{A. Traditional Method}

Traditional methods use RSS with other parameters as decision criteria. The algorithms based on RSS are easy to implement as they do not involve too much complexity.

In [12], K. Pahlavan, et al., have proposed decision model based on received signal strength (RSS). In this algorithm, the decision to transfer the mobile node from current network to another mainly depends upon received signal. The major drawback of received signal strength (RSS) algorithm is the generation of large numbers of handoff, because received signal strength (RSS) cannot be measured accurately due to path loss and fading of the signal. Also, these algorithms cannot offer the desired quality of service as they do not consider network condition and user preferences.

\section{B. User Centric Approaches}

The User Centric approaches considers only user preferences to achieve maximum user satisfaction. The preferences are given in the form of cost and quality of service (QoS). It chooses the best utility function for user satisfaction rather than for applications.

In [13], G. Calvagna, has proposed a user centric algorithm. In this, the actual transfer rate of each network is calculated by the mobile terminal. It uses the predicted rate and utility function to determine which network is best for a complete transfer of data with maximum utility.

In [14], J. Zhang, et al. have proposed a location-based vertical handoff decision algorithm for heterogeneous mobile networks to maximize user satisfaction by means of a utility function. They have predicted the mobility pattern of a mobile terminal based on its movement and location topology and have utilized this information for handoff decision based on the user satisfaction framework. The proposed scheme enhances the user satisfaction and reduces the harmful handoff. But the proposed work is user centric and enhances the user satisfaction without considering the network overloading, traffic \& congestion.

\section{Fuzzy Logic and Neural Network}

Fuzzy Logic (FL) and Neural Network (NN) are two concepts that allow coding in qualitative thinking of human experts to choose when and to which network for the implementation of vertical handoff algorithm. The advanced algorithm with improved efficiency and decision criteria can be developed for both real and nonreal applications by combining the Fuzzy and Neural networks. 
In [8], F. Siddiqui, et al., has proposed a decision model based on fuzzy and neural networks. In this algorithm, neural network is used as a baseline system. The GA is combined with fuzzy logic and neural network to select the best network at a given time. In this solution, a string must encode $\mathrm{n} * \mathrm{c}$ real valued parameter in which each coefficient encoded by 8 bits and scaled between [0 1]. After that the GA manipulates the most promising strings in its search for improved solutions.

In [15], X. Haibo, et al. have proposed a Novel terminal-controlled handover scheme in heterogeneous wireless networks. They have proposed two handoff scenarios: handoff from UMTS to WLAN and handoff from WLAN to UMTS using Mamdani fuzzy logic to find out a handoff factor. But it is difficult to define fuzzy sets for the network selection function.

In [16], Q. Song, et al. have proposed a quality of service negotiation-based vertical handoff decision scheme. In this, a counter serve as a dwell timer to ensure the conditions ( PRSS > RSS) to be consistently true. But it can store a fixed value, which may be too long if the mobile node's velocity is high. Moreover, the weight values in the merit function for finding the best possible target network are not adaptive with the metric values. But, for real situation the counter and the weight values should be adaptive in nature.

In [7], L. Bosoanca have proposed an intelligent handoff management process. It is based on Fuzzy Logic (FL), Multiple criteria (MC) and Analytic Hierarchy Process (AHP) and Always best connected (ABC) algorithm. The Always best connected (ABC) algorithm is used to initiate the handoff process. Once the handoff process is initiated, the information from the mobile and network (e.g. Quality of service (QoS), bandwidth, packet delay, packet loss, user preference, capabilities, battery, network interfaces, application used in real time or not, terminal location, speed etc.) is collected. The collected information is given as input to a Fuzzy Logic and the output of Fuzzy Logic is given to an Analytic Hierarchy Process (AHP) to analyze the output.

\section{Context Aware}

The Context aware algorithms choose the best network among the available network based on the mobile terminal and network information. They make a balance between user demand and network condition.

In [17], T. L. Saaty, et al., has proposed a decision algorithm based on Context Analytic Hierarchy Process (AHP). The handoff mechanism is designed for vertical handoff initiation and decision with respect to the changes in context. It is a much more complex algorithm and deals with a much difficult point which has not taken into account earlier.

\section{E. Functional Based}

Vertical handoff decisions based on a cost function measures the benefit obtained from switching.

In [18], the first policy enabled handover strategy is proposed by H.J. Wang in 1999, They have proposed a call admission policy based on network perspective and user perspective. From user perspective, the admission control provides facility to the user, i.e. required quality of service (QoS) level, bandwidth, minimum cost. Whereas from network perspective admission control forces the handover to a different network for achieving the load balancing between candidate networks. Although, there are various policies based proposal for handoff decision. Most of them consider the user perspective. These proposals increase the user satisfaction at the cost of network instability as user competes for network resources regardless of network condition. On the other hand, the network controlled algorithm ignores the user preferences and quality of service (QoS) requirement. Therefore, there should be an optimal admission control algorithm, which considers both user and network aspects. This algorithm makes a balance between user admission and network conditions. Therefore, it requires that the user must express their choices in the form of rule, not as value for switching to another network. The complexity arises due to complex rules which results in an ambiguous handoff decision.

In [19], P. Goyal, and S. K. Saxena have proposed dynamic decision model for vertical handoff decision algorithm. They have calculated a score function for each candidate network. The network having a highest value of score function is selected as "Best Network" to handoff all the current information to the selected network.

\section{F. Multiple Attributes Decision Making}

Multiple attributes decision algorithm chooses an alternative from a set of alternatives which are characterized in terms of their attributes. The various MADM methods are:

In [20], K. Savitha, et al., have propose a Simple additive weighting method (SAW). In this the overall score of a candidate network is determined by the weighted sum of all the attribute values. In this, handoff decision is based on the comparison between the neighbor network quality of service (QoS) and the mobile user quality of service (QoS) (i.e. offered bandwidth, processing delay, usage cost and jitter). The handoff decision depends on the weighted sum of all the attributes of a candidate network. They have worked on handoff decision phase to reduce the processing delay in the process of handover. But a very few parameters (offered bandwidth, processing delay, usage cost and jitter) are considered for handoff decision. Performance can be further enhanced by including the parameters like packet loss and error rate.

In [21], K. Radhika, et al., had proposed Gray Relational Analysis (GRA) to rank the candidate network and then selects the network with the highest ranking value. This model is based on Bayesian evolutionary game model. In this algorithm, when a mobile terminal achieves a signal from more than one wireless network, it performs network selection iteratively to achieve best quality of service (QoS) with minimum cost. The decision algorithm tries to find an equilibrium point at which the quality of network access service is maximized and the cost of service is minimized. This solution is 
termed as Bayesian Nash Equilibrium. In their algorithm, the handoff decision problem was solved as a noncooperative game between the mobile node and the access network that were available in the surrounding area of the mobile user. It considers terminal parameters such as quality of service (QoS) requirement of the mobile application along with the velocity of the mobile terminal and cost per bit offered by each network. The algorithm allows the mobile user to avail the highest quality of service (i.e. the highest bandwidth, supported velocity and lowest packet delay, jitter and bit error rate) with minimum cost per bit offered by each network. They reduce the handoff delay in scanning the available network with the help of a media independent handover framework. But, the authors have not considered the number of handoff made by mobile node. If the numbers of handoff are more than the specified limit, then it consumes more battery power, which is a crucial parameter.

In [22] J. Hwang et al., have proposed quality dependent vertical handover decision algorithm for fourth generation (4G) heterogeneous network. They have designed a decision function and cost factor calculation algorithms. The network with the highest quality and lowest cost is selected as the target network for handover.

In [23], D. He et al. proposed a simple and robust two step vertical handoff decision algorithms keeping in mind that mobile node have limited battery power, which is a critical parameter. In this, the handoff decision depends on dynamic new call blocking probability (DNCBP) and resources of a mobile node. For a resource poor mobile node, the handoff decision finds the candidate network by calculating the minimum service requirement function. It indicates whether the basic services required by the mobile node are supported by the available network or not. Whereas for resource rich mobile nodes extended vertical handoff function calculates the benefits gained by mobile terminal after switching. The algorithm is based on available bandwidth, dynamic new call blocking probability (DNCBP) and received signal strength (RSS) to choose the best network from the available network. It provides the optimum utilization of bandwidth. In future, we can use packet loss to enhance this approach.

In [24], P. Vetrivelan, and P. Narayanasamy, proposed a seamless media independent resilience triggering (SMRIT) framework for providing decision based on received signal strength (RSS), bandwidth, and transmission delay and packet loss. It provides the seamless roaming across the heterogeneous network through the media independent handover framework without user intervention. The selection of network is based on the highest value of quality factor, which is a function of bandwidth, delay, cost \& throughput. The proposed framework, aims to minimize new call blocking probability (NCBP), handoff call dropping probability (HCDP) and to efficiently utilize the system resources. The algorithm accepts or rejects the new call to avoid the overloading in a network. Their framework has been simulated by using NS3 and it greatly reduces the transmission delay, packet loss, decision processing delay, handover blocking rate and new call dropping rate. But in this algorithm, new call blocking probability (NCBP) decreases with a fixed adaptability ratio $(\beta)$. In future, there should be an algorithm which should define the optimal value of $(\beta)$ which will suit for real time $4 \mathrm{G}$ wireless network.

In [5], P. Payaswini, and D. H. Manjaiah have proposed a media independent vertical handoff decision algorithm based on dynamic weights, mobile node prefence and network condition to improve throughput, handoff latecy and packet drop rate.

\section{COMPARATIVE ANALYSIS}

Comparison of all vertical handoff decision algorithm is tabulated in Table 1. It outlines the name of the algorithm, method used for decision, input parameters, complexity of algorithms, reliability, advantages and their drawbacks. Traditional method considers only few numbers of parameters. Whereas User centric approach considers the user related parameter and preferences. On the other hand, Multi-attribute decision algorithm considers the maximum number of parameters for decision. Some uses Fuzzy based methods. Which is an intelligent approach. The Context aware decision algorithm considers the user and network context information. This is an efficient method, but with more constraints. The cost function based method uses both static and dynamic parameters for decision making. But there are only few papers which consider the predictive received signal strength of current network and neighbor network.

\section{PRoposed AlgorithM}

We have proposed an algorithm based on predicted received signal strength (PRSS), hysteresis margin and dwell time [27]. The inclusion of hysteresis margin and dwell time in predicted received signal strength (PRSS) helps in reducing the early handoff, ping- pong effect, decision delay and utilization rate. The received signal strength is predicted with the help of Adaptive NeuroFuzzy Inference (ANFIS) algorithm. In this, the target network selection depends upon bandwidth, power consumption, cost, network condition, user preference and type of application. By the implementation of our algorithm, we can provide a mechanism that can select the best network at the appropriate time and provides the uninterrupted services to mobile users, that allows connectivity between universal mobile telecommunication system (UMTS) and wireless local area network (WLAN). We have simulated our results in MATLAB environment and verified them by comparing it with a hysteresis based vertical handoff algorithm [26]. The proposed algorithm is divided into three phasesHandoff necessity estimation, Network analysis and Handoff execution phase.

\section{A. Handoff necessity estimation}


In this phase, received signal strength (RSS) is predicted and is observed for a specified duration. If received signal strength (RSS) remains stable for a dwell time and hysteresis margin duration, then only handoff algorithm will be triggered. After this, candidate networks (eligible network) are selected from the available network. A candidate network is a network that can support the services required by the user. It can be calculated as:

$$
\mathrm{CN}_{1}=\mathrm{f}\left(\mathrm{b}_{1}-\mathrm{b}_{\mathrm{th}}\right) \cdot \mathrm{f}\left(\mathrm{PRSS}_{1}-\mathrm{RSS}_{\mathrm{th}}\right) \cdot \mathrm{f}\left(\mathrm{po}_{1}-\mathrm{po}_{\mathrm{th}}\right) \mathrm{f}\left(\mathrm{co}_{1}-\mathrm{co}_{\mathrm{th}}\right)
$$

\section{Where}

$b_{1}, P_{R S S}, p o_{1}, c o_{1}=$ bandwidth, predicted received signal strength, power consumption and cost of a particular network 1 . $\mathrm{b}_{\mathrm{th}}, \quad \mathrm{Rss}_{\mathrm{th}}, \quad \mathrm{po}_{\mathrm{th}}, \quad \mathrm{co}_{\mathrm{th}}=$ predefined thresholds of bandwidth, received signal strength, power requirement and service cost to support the requested traffic class of the respective network.

\section{B. Network analysis}

In network analysis phase all the candidate networks are analyzed in terms of security, cost, power, network condition and user preferences. For this, handoff factor is calculated for all eligible network and a network having the highest value of handoff factor is selected as an optimum target network. Handoff factor (HF) can be defined as improvement gained by the user after switching to a new network regarding to the running services. It can be calculated as:

Table 1. Comparasions of Various Vertical Handoff Decision Algorithms

\begin{tabular}{|c|c|c|c|c|c|c|}
\hline Method & Input parameters used & $\begin{array}{c}\text { Handover } \\
\text { target selection } \\
\text { area } \\
\end{array}$ & Complexity & Reliability & Advantages & Drawbacks \\
\hline $\begin{array}{l}\text { Traditional } \\
\text { Method }\end{array}$ & RSS with threshold & $\begin{array}{l}\text { Candidate } \\
\text { network with } \\
\text { the highest } \\
\text { stable RSS }\end{array}$ & Simple & $\begin{array}{c}\text { Reduced reliability } \\
\text { because of fluctuation in } \\
\text { RSS }\end{array}$ & $\begin{array}{l}\text { Reduced number } \\
\text { of handoff } \\
\text { blocking }\end{array}$ & $\begin{array}{l}\text { Low } \\
\text { throughput, } \\
\text { also the user } \\
\text { preferences are } \\
\text { not considered }\end{array}$ \\
\hline $\begin{array}{l}\text { User Centric } \\
\text { Approach }\end{array}$ & $\begin{array}{l}\text { User related parameters } \\
\text { and preferences, RSS, } \\
\text { bandwidth, power }\end{array}$ & $\begin{array}{l}\text { Candidate } \\
\text { network with } \\
\text { the highest } \\
\text { value of user } \\
\text { satisfaction }\end{array}$ & Complex & $\begin{array}{c}\text { Reduced reliability } \\
\text { because it considers only } \\
\text { user preferences. For a } \\
\text { good handoff algorithm, } \\
\text { network conditions and } \\
\text { constraints should also be } \\
\text { taken into account. }\end{array}$ & $\begin{array}{l}\text { Maximize the } \\
\text { user's level of } \\
\text { satisfaction. }\end{array}$ & $\begin{array}{c}\text { Network } \\
\text { parameters are } \\
\text { not considered }\end{array}$ \\
\hline $\begin{array}{l}\text { Fuzzy \& } \\
\text { Neural } \\
\text { based } \\
\text { approach }\end{array}$ & $\begin{array}{l}\text { Bandwidth, RSS, jitter, } \\
\text { type of application (real } \\
\& \text { non-real), delay, error } \\
\text { rate }\end{array}$ & $\begin{array}{l}\text { Candidate } \\
\text { network with } \\
\text { the highest } \\
\text { overall } \\
\text { performance }\end{array}$ & $\begin{array}{c}\text { Very } \\
\text { complex }\end{array}$ & $\begin{array}{l}\text { High reliability because of } \\
\text { intelligent system. }\end{array}$ & $\begin{array}{l}\text { Excellent } \\
\text { performance for } \\
\text { delay sensitive } \\
\text { application. }\end{array}$ & $\begin{array}{l}\text { More complex } \\
\text { algorithm. }\end{array}$ \\
\hline $\begin{array}{l}\text { Context } \\
\text { Aware }\end{array}$ & $\begin{array}{l}\text { User information, user } \\
\text { device and network } \\
\text { context information }\end{array}$ & $\begin{array}{l}\text { Candidate } \\
\text { network with } \\
\text { the highest } \\
\text { overall } \\
\text { performance }\end{array}$ & Complex & $\begin{array}{l}\text { High reliability, but there } \\
\text { are more constraints. }\end{array}$ & $\begin{array}{c}\text { Minimum } \\
\text { number of } \\
\text { handoff and less } \\
\text { delay sensitive } \\
\text { application. }\end{array}$ & $\begin{array}{l}\text { Multimedia } \\
\text { traffic is not } \\
\text { considered. }\end{array}$ \\
\hline $\begin{array}{l}\text { Cost } \\
\text { Function } \\
\text { Algorithm }\end{array}$ & $\begin{array}{c}\text { Static and Dynamic } \\
\text { parameters such as cost, } \\
\text { bandwidth, power } \\
\text { consumption, RSS. }\end{array}$ & $\begin{array}{c}\text { Candidate } \\
\text { network with } \\
\text { the highest } \\
\text { score value. }\end{array}$ & Simple & $\begin{array}{c}\text { Reduced reliability } \\
\text { because of the difficulty in } \\
\text { accurate measuring of } \\
\text { some parameters. }\end{array}$ & $\begin{array}{l}\text { Simplest and } \\
\text { fastest handoff } \\
\text { process. }\end{array}$ & $\begin{array}{l}\text { Ambiguous } \\
\text { handoff } \\
\text { decision. }\end{array}$ \\
\hline $\begin{array}{l}\text { Multi- } \\
\text { Attribute } \\
\text { Decision }\end{array}$ & $\begin{array}{l}\text { Network related and } \\
\text { system related parameter } \\
\text { (e.g. bandwidth, power, } \\
\text { cost, delay, jitter, real \& } \\
\text { non-real application) }\end{array}$ & $\begin{array}{l}\text { Candidate } \\
\text { network with } \\
\text { the highest } \\
\text { overall } \\
\text { performance }\end{array}$ & Complex & $\begin{array}{l}\text { High reliability but there } \\
\text { is more constraints. }\end{array}$ & $\begin{array}{c}\text { Reduced } \\
\text { computational } \\
\text { overhead and } \\
\text { handoff latency. }\end{array}$ & $\begin{array}{l}\text { Quality of } \\
\text { service } \\
\text { parameters are } \\
\text { not considered } \\
\text { and complex } \\
\text { algorithm. }\end{array}$ \\
\hline
\end{tabular}

$$
\begin{aligned}
& \frac{\mathrm{W}_{\mathrm{sc}}\left(\mathrm{sc}_{1}\right)}{\max \left(\left(\mathrm{sc}_{1}\right), \ldots \ldots .\left(\mathrm{sc}_{\mathrm{m}}\right)\right)}+\frac{\mathrm{W}_{\mathrm{co}}\left(1 / \mathrm{co}_{1}\right)}{\max \left(\left(\frac{1}{\mathrm{co}_{1}}\right), \ldots \ldots .\left(\frac{1}{\mathrm{co}_{\mathrm{m}}}\right)\right)}+\frac{\mathrm{W}_{\mathrm{po}}\left(\mathrm{po}_{1}\right)}{\max \left(\left(\mathrm{po}_{1}\right), \ldots \ldots . .\left(\mathrm{po}_{\mathrm{m}}\right)\right)}+ \\
& \frac{\mathrm{W}_{\mathrm{nc}}\left(\mathrm{nc}_{1}\right)}{\max \left(\left(\mathrm{nc}_{1}\right), \ldots \ldots .\left(\mathrm{nc}_{\mathrm{m}}\right)\right)}+\frac{\mathrm{W}_{\mathrm{np}}\left(\mathrm{np}_{1}\right)}{\max \left(\left(\mathrm{np}_{1}\right), \ldots \ldots .\left(\mathrm{np}_{\mathrm{m}}\right)\right)}
\end{aligned}
$$

Where $s c_{l}=$ Security of $1^{\text {th }}$ network

$c O_{l}=$ Cost of $1^{\text {th }}$ network

$p o_{l}=$ Power consumption of $\mathrm{l}^{\text {th }}$ network

$n c_{l}=$ Network condition of $1^{\text {th }}$ network

$n p_{l}=$ Network performance of $1^{\text {th }}$ network

$\mathrm{m}=$ Size of candidate network set 


\section{Target Network selection}

Finally, the decision phase is used to select an optimum target network. In this phase, all the current connections are transferred to the selected target network. We have designed different policies for UMTS \& WLAN networks depending upon the type of application and network characteristics. The target network is selected from the available candidate network that have stable and sufficient PRSS for a dwell time duration and the largest value of handoff factor.

\section{SiMULATION SETUP}

The simulation is carried out in MATLAB Version 7.12.0.635 (R2011a) to check the performance of the proposed algorithm. In the simulation, we have considered an overlaid architecture of single UMTS, fourteen WLAN and three Wi-MAX to cover an area of $3000 * 3000 \mathrm{~m}$ as shown in Fig. 4. The transmission range of UMTS covers an area of $3000 \mathrm{~m}$, Wi-MAX covers an area of $1000 \mathrm{~m}$ and WLAN covers an area of $100 \mathrm{~m}$. The bandwidth of UMTS, WLAN and Wi-MAX are $384 \mathrm{~kb} / \mathrm{s}$, $11 \mathrm{Mb} / \mathrm{s}$, and $15 \mathrm{Mb} / \mathrm{s}$, respectively. The number of mobile nodes ranges from 1 to 10 , and are configured to use interfaces UMTS, Wi-Fi, and Wi-MAX. The trajectory of mobile node is fixed from point $\mathrm{A}$ to $\mathrm{C}$ with random velocity from 1 to $50 \mathrm{~m} / \mathrm{s}$. The received signal strength is sampled at every $0.1 \mathrm{sec}$.

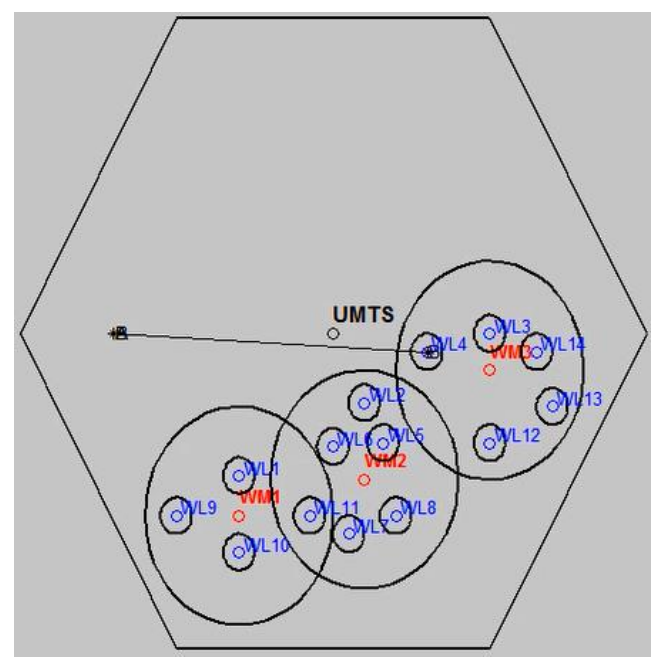

Fig.4. Overlaid Wireless Network of WLAN,Wi-MAX and UMTS

\section{RESUlT AND DISCUSSION}

We have proposed an algorithm based on PRSS, hysteresis margin and dwell time [27]. To evaluate the performance of a proposed method, we have considered four metrics i.e. probability of unnecessary handoff, probability of handoff failure, number of handoff and decision delay and have made comparison with a Hysteresis based vertical handoff algorithm [26] [28].

\section{A. Probability of unnecessary handoff}

An unnecessary handoff leads to excessive resource consumption. It occurs if the traveling time of mobile node inside the WLAN is smaller than the total handoff delay time. Total handoff is the sum of the handoff delay from the cellular network to WLAN $\left(\mathrm{td}_{\mathrm{c}}\right)$ and of handoff delay from WLAN to cellular network $\left(\operatorname{td}_{\mathrm{W}}\right)$. Our algorithm reduces the probability of unnecessary handoff by initiating the handoff only when a mobile node receives a stable RSS. Fig. 5. shows the probability of unnecessary handoff for Hysteresis based method and Proposed method. The probability of unnecessary handoff for Hysteresis based method and Proposed method can be calculated as:

$$
\mathrm{P}_{\mathrm{Uh}_{\text {hys }}}=\left\{\begin{array}{l}
1, \mathrm{v}\left(\mathrm{t}_{\mathrm{dC}}+\mathrm{t}_{\mathrm{dW}}\right)>2 \mathrm{~d}_{\text {hys, }} \\
\frac{2}{\pi} \sin ^{-1}\left(\frac{\mathrm{v}\left(\mathrm{t}_{\mathrm{dC}}+\mathrm{t}_{\mathrm{dW}}\right)}{2 \mathrm{~d}_{\text {hys }}}\right), 0 \leq \mathrm{v}\left(\mathrm{t}_{\mathrm{dC}}+\mathrm{t}_{\mathrm{dW}}\right) \leq 2 \mathrm{~d}_{\text {hys }}
\end{array}\right\}
$$

$\mathrm{P}_{\text {Uhf }_{\text {PRSS+Dwell hys }}}=\left\{\begin{array}{l}1, \mathrm{v}\left(\mathrm{t}_{\mathrm{dC}}+\mathrm{t}_{\mathrm{dW}}\right)>2 \mathrm{~d}_{\text {PRSS }+ \text { Dwell }+ \text { hys }} \\ \frac{2}{\pi} \sin ^{-1}\left(\frac{\mathrm{v}\left(\mathrm{t}_{\mathrm{dC}}+\mathrm{t}_{\mathrm{dW}}\right)}{2 \mathrm{~d}_{\text {PRSS+Dwel hys }}}\right), 0 \leq \mathrm{v}\left(\mathrm{t}_{\mathrm{dC}}+\mathrm{t}_{\mathrm{dW}}\right) \leq 2 \mathrm{~d}_{\text {PRSS+Dwell hys }}\end{array}\right\}$

$$
\mathrm{d}_{\text {hys }}=10 \frac{\mathrm{P}_{\mathrm{TX}}-\mathrm{RSS}_{\text {hys }}+\mathrm{H}_{\text {margin }}}{10^{\beta}}
$$

where

$$
P_{U h f_{h y s}}=\text { probability of unnecessary handoff for }
$$

Hysteresis based method

$P_{U h f_{P R S S+D w e l l} \text { hys }}=$ probability of unnecessary handoff for Proposed method

$d_{P R S S+D w e l l+h y s}=$ distance between the mobile node and the WLAN access point when handoff occurs.

$d_{\text {hys }}=$ distance between the mobile node and WLAN access point when handoff occurs.

$t_{d W}=$ handover delay from cellular network to WLAN network

$t_{d C}=$ handover delay from cellular network to WLAN network

\section{B. Probability of handoff failure}

A handoff failure occurs when the traveling time inside the WLAN is smaller than the handoff delay from cellular network to WLAN network $\left(\operatorname{td}_{\mathrm{c}}\right)$. Fig. 6 shows the probability of handoff failure for Hysteresis based method and Proposed method. It is calculated as: 


$$
\begin{aligned}
& \mathrm{P}_{\mathrm{hf}_{\text {hys }}}=\left\{\begin{array}{l}
1, \mathrm{t}_{\mathrm{dC}}>2 \mathrm{~d}_{\mathrm{hys},} \\
\frac{2}{\pi} \sin ^{-1}\left(\frac{\mathrm{vt}_{\mathrm{dC}}}{2 \mathrm{~d}_{\mathrm{hys}}}\right), 0 \leq \mathrm{vt}_{\mathrm{dC}} \leq 2 \mathrm{~d}_{\text {hys }}
\end{array}\right\} \\
& \mathrm{P}_{\text {hf }_{\text {PRSS+Dwell hys }}}=\left\{\begin{array}{l}
1, \mathrm{t}_{\mathrm{dC}}>2 \mathrm{~d}_{\text {PRSS }+ \text { Dwell +hys }} \\
\frac{2}{\pi} \sin ^{-1}\left(\frac{\mathrm{vt}_{\mathrm{dC}}}{2 \mathrm{~d}_{\text {PRSS }+ \text { Dwell }+ \text { hys }}}\right), 0 \leq \mathrm{vt}_{\mathrm{dC}} \leq 2 \mathrm{~d}_{\text {PRSS }+ \text { Dwell +hys }}
\end{array}\right\}
\end{aligned}
$$

Where

$P_{h f_{P R S S+D w e l l}+h y s}=$ probability of handoff failure for hysteresis based method

$P_{h f_{P R S S+D w e l l+h y s}}=$ probability of handoff failure for proposed method

$P_{T X}=$ Transmitted power of WLAN access point

$\beta=$ path loss exponent

$v=$ velocity of mobile node

\section{Number of handoff}

Fig. 7 shows that, in a proposed algorithm, numbers of handoffs are reduced greatly because of reduced fluctuation in received signal strength as handoff occurs only when PRSS remains stable for the whole dwell timer duration.

But in case of the hysteresis based algorithm, handoff occurs for all values of received signal strength which is greater than hysteresis margin. Also, the handoff condition is checked for each and every sampling point. Therefore, the number of handoffs as well as decision delay is more in hysteresis based vertical handoff algorithm as compared to the proposed algorithm as shown in Fig. 8.

\section{Decision delay}

The presence of shadow effect increases the fluctuation and uncertainty of the RSS. Due to this, number of handoff increases as the user connection oscillates between these networks. It increases the number of sampling points between first handoff $\left(\mathrm{K}_{\mathrm{f}}\right)$ and last handoff $\left(\mathrm{K}_{\mathrm{L}}\right)$. Fig. 10 shows that, for a hysteresis based algorithm decision delay decreases as the velocity of mobile node increases because of larger sampling distance and hence RSS increases rapidly with respect to time which makes lesser sampling points between $K_{f}$ and $\mathrm{K}_{\mathrm{L}}$. So it has less decision delay.

In proposed algorithm handoff occurs only when the PRSS of neighbor network remains constant for a predefined hysteresis margin and dwell time period. Therefore we have very few handoff points between $\mathrm{K}_{\mathrm{f}}$ and $\mathrm{K}_{\mathrm{L}}$. Hence decision delay is small in a proposed algorithm as compared to a decision algorithm based on hysteresis method as shown in Fig. 9.

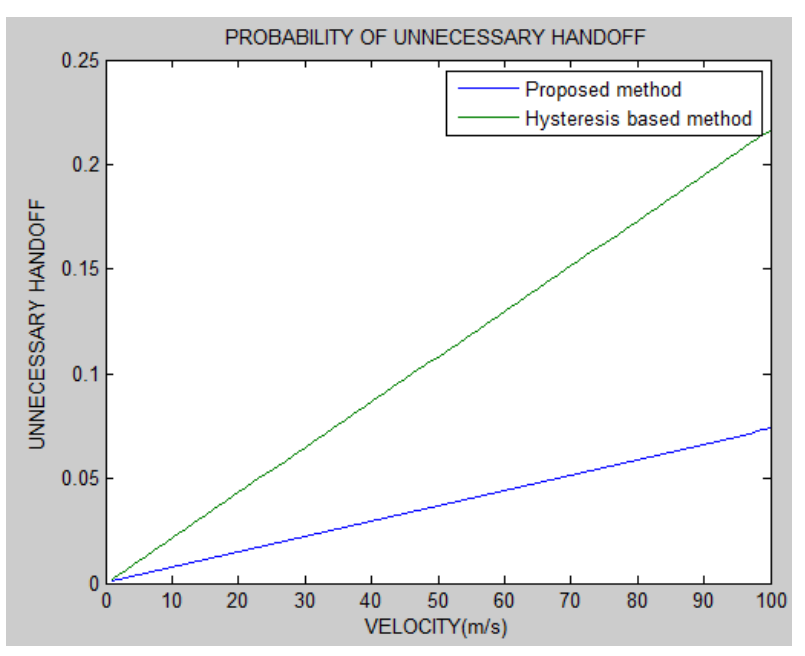

Fig.5. Probability of Unnecessary Handoff

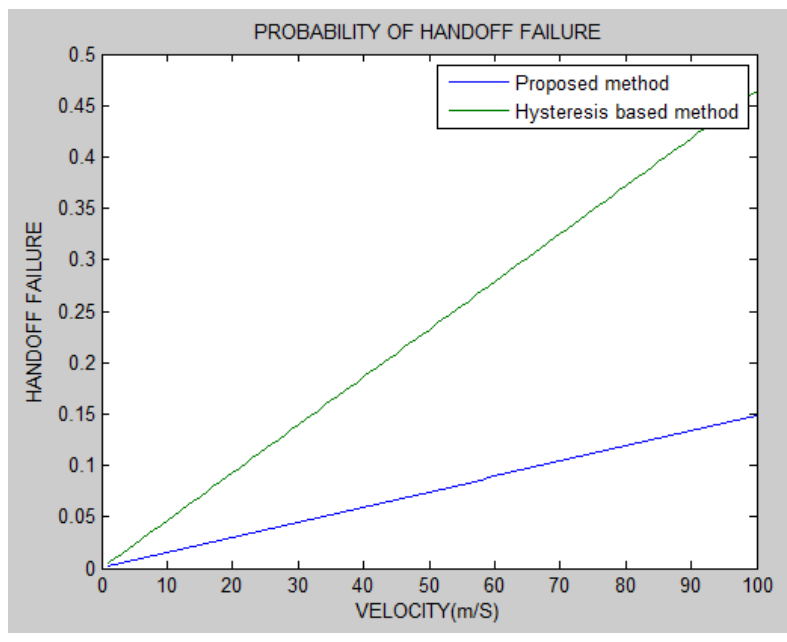

Fig.6. Probability of Handoff Failure

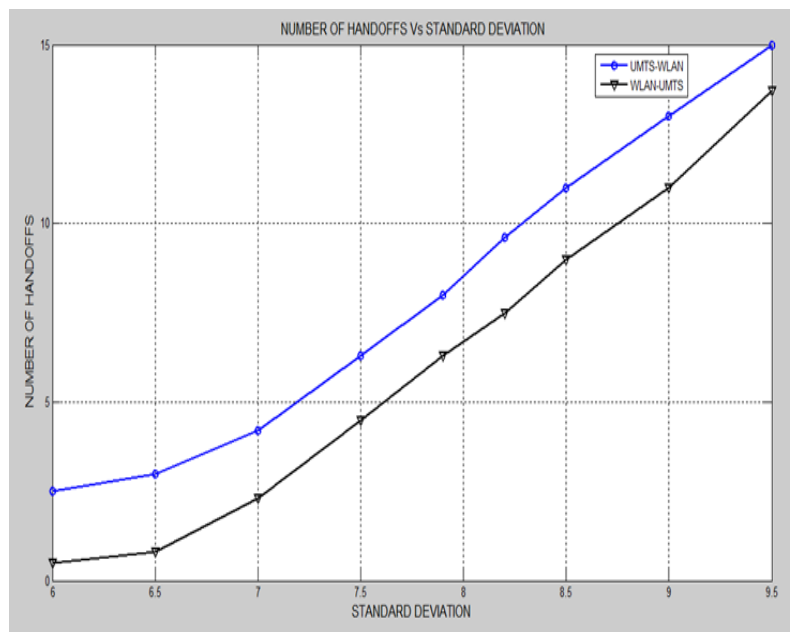

Fig.7. Number Of Handoff vs. Standard Deviation (Proposed Algorithm) 


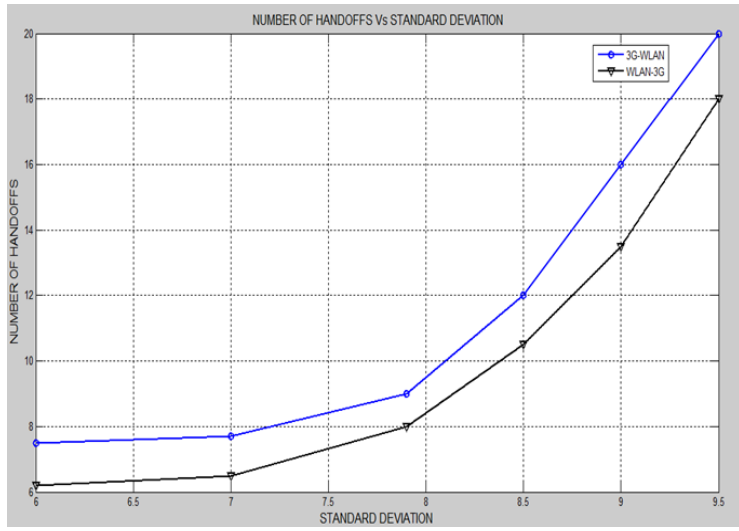

Fig.8. Number of Handoff VS. Standard Deviation (Hysteresis Based Algorithm)

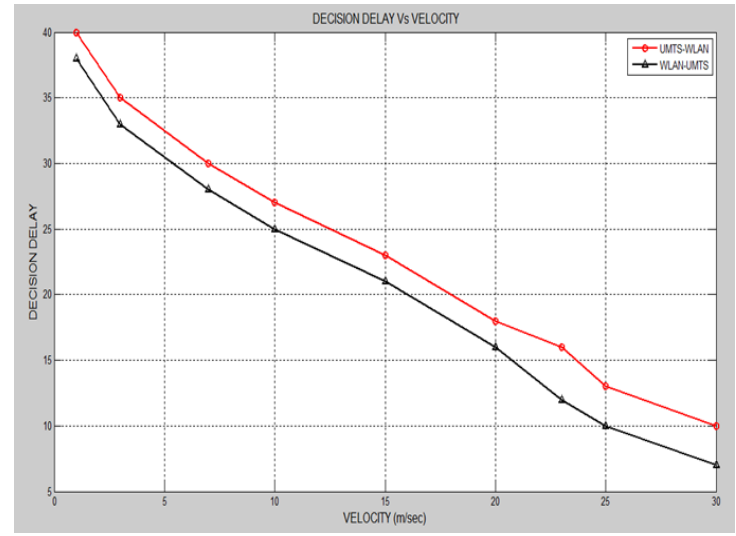

Fig.9. Decision Delay VS. Velocity (Proposed Algorithm)

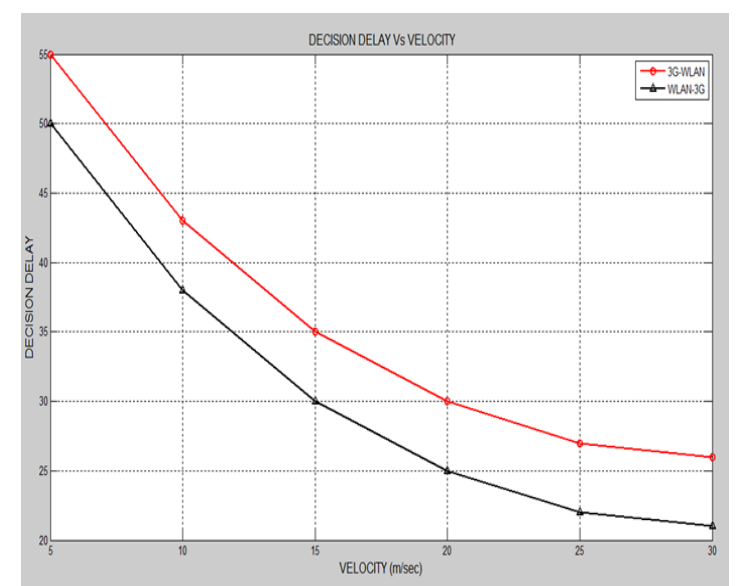

Fig.10. Decision Delay VS. Velocity (Hysteresis Based Algorithm)

\section{RESEARCH IsSUES}

The most important issue in vertical handoff decision algorithm is to design handoff policy that can lead to the best overall performance. There are various policies that select the target network which provides highest throughput. But, they ignore various metrics that have same importance as throughput. These metrics are power consumption of using a network, service cost, packet delay, handoff latency, connection reliability and stability. Next generation wireless network is a integration of various heterogeneous access networks. Therefore, in order to provide seamless, continuous services many challenging research issues and challenges need to be resolved. There are various challenging issues like When to switch?, VHO policies, Seamless handoff, Packet loss, Load balancing between networks, QoS guarantees, security and authentication, handoff latency etc. Few of them are explained as follows:

\section{A. Handover rate}

It is the total number of handovers experienced by a mobile node while moving from one network to another. Ideally, there should be only one handoff, which is to be executed at the boundary of the network. But due to fluctuations in received signal strength, user preference, security and bandwidth requirement, the mobile node undergo more than one handoff.

\section{B. Probability of handover failure}

Handoff failure occurs when the received signal strength from serving network goes below a minimum acceptable level, before the handoff process gets completed. Handoff failure mainly occurs due to poorly designed handoff policies and delayed handoff triggering.

\section{Probability of unnecessary handoff}

Unnecessary handoff occurs due to wrong handoff necessity estimation, due to which handoff algorithm is initiated too early or too late. It results in the excessive signalling overhead and wastage of network resources. Hence, to utilize network resources properly handoff algorithm must be initiated at an appropriate time.

\section{Resource utilization}

In a cellular network, capacity is enhanced by decreasing the cell size. But, smaller cell size increases the problem of false handover initiation. Due to frequent handoff initiation, the resources of serving network are not utilized fully.

\section{E. Ping-Pong effect}

Received signal strength (RSS) gets oscillated due to path losses and shadow effect. Fluctuating received signal strength (RSS) give rise to a problem of frequent handovers or unstable connection. The frequent handovers between access networks due to fluctuating RSS is known as ping-pong effect. It increases the handoff rate, therefore needs to be mitigated through efficient handoff policies.

\section{F. Security Issues}

In a wireless transmission, the data are broadcast over the air interface and people do not have control over the transmission boundaries. Therefore, when a sensitive data is transmitted, it should be transferred in a secured manner.

\section{G. QoS Issues}

Mobile nodes carrying real time and non-real time traffic should be provided with guaranteed QoS. 


\section{H. TCP Performance Issues}

When a handoff occurs from a low bandwidth, high data rate network to a high bandwidth, low data rate network then functioning of TCP gets affected. Therefore TCP performance should be considered.

\section{CONCLUding REMARKS \& FUtuRE RESEARCH DIRECTION}

The aim of heterogeneous wireless network is to offer high quality services. Vertical handoff is a most challenging issue for a heterogeneous network to allow seamless roaming for mobile nodes. In this paper, We have concluded that RSS based algorithm could not provide the desired quality of service. Also, the accuracy of these algorithms based on the measurement of RSS. Therefore, more powerful techniques must be used for calculating RSS. The User centric approach does not consider the network condition. An optimum handoff decision algorithm must make a balance between user preference and network condition. The fuzzy and neural based approaches can trigger the handoff at an appropriate time. But, it is very difficult to design Fuzzy set rules. Therefore, it is necessary to design an optimum handoff decision algorithm which has low power consumption, balanced network load, network security, user preferences, throughput and low handoff latency. We have proposed an algorithm to select the target network depending upon the bandwidth, power consumption, cost, network condition, user preference and type of application to achieve the desired quality of service requested by the user. In this algorithm, we have used predicted received signal strength (PRSS) of service network and neighbor network to initiate the handoff at an appropriate time. The inclusion of hysteresis margin and dwell timer reduces the effect of fluctuating RSS and thus reduces the number of unnecessary handoff. Also the pre-calculation of candidate network list further reduces the processing delay. This algorithm selects the optimum target network and considerably reduces the number of vertical handoff and decision delay, probability of unnecessary handoff and probability of false handoff.

\section{REFERENCES}

[1] A. Bhuvaneswari, and E.G.D.P. Raj, "An overview of vertical handoff decision making algorithms", International Journal of Computer Network and Information Security, vol. 4, No. 9, pp.55, Aug. 2012.

[2] M. Kassar, B. Kervella, and G. Pujolle, "An overview of vertical handover decision strategies in heterogeneous wireless networks", Computer Communications, vol. 31, no.10, pp. 2607-2620, June. 2008.

[3] L. Huang, S. Kumar, and C.J. Kuo, "Adaptive resource allocation for multimedia services in wireless communication networks", International Conference on Distributed Computing Systems, pp. 307-312, IEEE, April 2001.

[4] S.Y.Tisgaonkar, C. Hung, and B. Bing, "Intelligent handoff management with interference control for next generation wireless systems", In Proceedings of the 43rd annual Southeast regional conference, Volume 2, pp. 1-6, ACM, March 2005.

[5] L.J. Chen, T. Sun, B. Chen, V. Rajendran, and M. Gerla, "A smart decision model for vertical handoff", In Proceedings of the 4th International Workshop on Wireless Internet and Reconfigurability, Athens, Greece, May 2004.

[6] N. Krichene, and N. Boudrigssa, "Securing roaming and vertical handover in fourth generation networks", Third International Conference on Network and System Security, NSS'09, pp. 225-23, IEEE, October 2009.

[7] L. Bosoanca, and A. Vargatu, "An Overview of Vertical Handoff Decision Algorithms in NGWNs and a new Scheme for Providing Optimized Performance in Heterogeneous Wireless Networks", Informatica Economica, vol.15, no.1, p.5, Jan. 2011.

[8] F. Siddiqui, S. Zeadally, H. El-Sayed, and N. Chilamkurti, "A dynamic network discovery and selection method for heterogeneous wireless networks", International Journal of Internet Protocol Technology, vol. 4, no. 2, pp.99-114, Jan. 2009.

[9] J. McNair, and F. Zhu, "Vertical handoffs in fourthgeneration multinetwork environments", Wireless Communications, IEEE, vol. 11, no. 3, pp.8-15, June 2004.

[10] B. Ma, X. Liao, and X. Xie, "Vertical handoff algorithm based on type-2 fuzzy logic in heterogeneous networks", Journal of Software, vol. 8, no.11, pp.2936-2942, Jan. 2013.

[11] B. Bhowmik, "A Comparison Study on Selective Traffic Models with Handoff Management Scheme for Wireless Mobile Network Infrastructure", vol. 2, pp. 66-72, Jan. 2013, DOI: 10.5815/ijitcs.2013.02.07.

[12] K. Pahlavan, P. Krishnamurthy, A. Hatami, M. Ylianttila, J. Makela, R. Pichna, J. Vallstron, "Handoff in hybrid mobile data networks", Personal Communications, IEEE, vol. 7, no. 2, pp.34-47, Apr. 2000.

[13] A. Calvagna, and G. Di Modica, "A user-centric analysis of vertical handovers", In Proceedings of the 2nd ACM international workshop on Wireless mobile applications and services on WLAN hotspots, pp. 137-146, ACM, October 2004.

[14] J. Zhang, J. H.C. Chan, and V. Leung, "Wlc14-6: A location-based vertical handoff decision algorithm for heterogeneous mobile networks", In Global Telecommunications Conference, GLOBECOM'06, pp. 15, IEEE, November 2006.

[15] X. Haibo, T. Hui and Z. Ping, "A Novel TerminalControlled Handover Scheme in Heterogeneous Wireless Networks", Computers and Electrical Engineering, vol. 36, no.2, pp.269-279, Mar. 2010.

[16] Q. Song and A. Jamalipour," A Quality of Service Negotiation-based Vertical Handoff Decision Scheme in Heterogeneous Wireless Systems, European Journal of Operational Research, vol. 191, no.3, pp.1059-1074, Dec. 2008

[17] T. L. Saaty, "How to make a decision: The Analytic Hierarchy Process", European Journal of Operational Research, vol. 48, no. 1, pp. 9-26, Sep. 1990.

[18] H.J. Wang, R.H. Katz, and J. Giese, "Policy-enabled handoffs across heterogeneous wireless networks", Second IEEE Workshop on Mobile Computing Systems and Applications, Proceedings, WMCSA'99, pp. 51-60, IEEE, February 1999.

[19] P. Goyal, and S.K. Saxena, "A dynamic decision model for vertical handoffs across heterogeneous wireless networks", World academy of science engineering and technology, vol. 31, no. 677-682, pp.3-1, July 2008. 
[20] K. Savitha, C. Chandrasekar, "Grey Relation Analysis for Vertical Handover Decision Schemes in Heterogeneous Wireless Networks", European Journal of Scientific Research, ISSN:1450-216X, vol. 54, no. 4, pp. 560-568, 2011.

[21] K. Radhika, A. V. Reddy, "AHP and Group Decision Making for Access Network Selection in Multi-Homed Mobile Terminals", International Journal on Computer Science and Engineering (IJCSE), ISSN : 0975-3397, vol. 3, no. 10, October 2011.

[22] J.Y. Hwang, J. Oh, and Y. Han, "A two-step vertical handoff algorithm in heterogeneous traffic and systems", In Vehicular Technology Conference, 2007, VTC-2007 Fall, 2007 IEEE 66th, pp. 1543-1547), IEEE, September 2007.

[23] D. He, C. Chi, S.Chan, C. Chen, J. Bu, and M., Yin, "A simple and robust vertical handoff algorithm for heterogeneous wireless mobile networks", Wireless Personal Communications, vol.59, no.2, pp.361-373,Jul 2011.

[24] P. Vetrivelan, and P. Narayanasamy, "SMIRT with Call Admission Control (CAC) based vertical handover decision for seamless mobility in multi-access $4 \mathrm{G}$ heterogeneous wireless overlay networks", IMECS, Hong Kong., 2012.

[25] P. Payaswini, and D.H. Manjaiah, "Dynamic Vertical Handoff Algorithm Using Media Independent Hando-ver Service for Heterogeneous Network", International Journal of Information Technology and Computer Science (IJITCS), vol. 6, no. 12, pp. 46-52, Nov. 2014, DOI: 10.5815/ijitcs.2014.12.06.

[26] S. Reddy, and S. D. Roy, "Vertical Handoff Decision Algorithms in Integrated Heterogeneous Networks," International Journal of Energy, Information \& Communications, vol. 4, no. 2, Apr. 2013.

[27] J. Verma, and I. Kashyap, "Vertical handoff decision algorithm based on PRSS and dwell time", International Journal of Computer Network and Information Security,in press.
[28] X. Yan, Y.A. Sekercioglu, and N. Mani, "A method for minimizing unnecessary handovers in heterogeneous wireless networks" InWorld of Wireless, Mobile and Multimedia Networks, 2008. WoWMoM 2008. 2008 International Symposium on a (pp. 1-5). IEEE.

\section{Authors' Profiles}

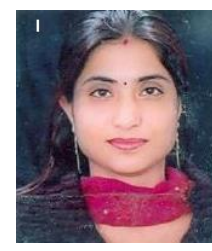

Jyoti verma completed her Masters Degree in Electronics \& Communication Engineering in the years 2009. She has 5 years of teaching experience at Manav Rachna International University, Faridabad, India. Currently, she is doing her research in the area of Wireless Networks under the guidance of Dr. Indu Kashyap.

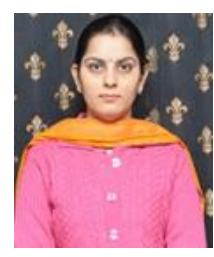

Dr. Indu Kashyap completed her Doctorate in Computer Science in the year 2012. She has around Nine years of Academic experience in the field of Computer Science. She is Currently working as Associate Professor in the Department of Computer Science and Engineering at Manav Rachna International University, Faridabad, India. Her research interest includes Wireless networking, Mobile computing, Computer Communication and Networks. She has published several papers in National, International Journals and Conferences related to Computer Science and has been a reviewer member in Manav Rachna International Journals.

Manuscript received February 25, 2016; revised March 25, 2016; accepted March 28, 2016.

How to cite this paper: Jyoti Madaan, Indu Kashyap,"Vertical Handoff with Predictive Received Signal Strength in Next Generation Wireless Network", International Journal of Computer Network and Information Security(IJCNIS), Vol.8, No.8, pp.27-38, 2016.DOI: 10.5815/ijcnis.2016.08.04 